with rectifiers, various types of converters and straight a.c. motors are in use experimentally in France, and some of these have been found to have special advantages for certain kinds of traffic.

The low-frequency, single-phase a.c. commutator motor is considered by some to have better charac. teristics than the d.c. machine for main-line work, and the development of the former to operate satisfactorily on $50 \mathrm{c} / \mathrm{s}$. has made considerable progress during the past few years in France. This type may yet become a serious rival to the d.c. series machine.

Up to now, however, the rectifier locomotive has given the most promising resultis, and has been found to have unexpected operating advantages over even its d.c. rival. On the Valenciennes-Thionville line, $B_{0}-B_{0}$ type mixed-traffic locomotives with 'Ignitron' rectifiers and having 84 tonnes adhesive weight haul freight trains of $\mathrm{I}, 400$ tonnes, whereas the absolute maximum loarting of a modern $1,500-\mathrm{V}$. d.c. locomotive of the same type and weight would be 900 tonnes only. This is due to improved adhesion characteristics at starting and at low speeds.

The motors used in rectifier locomotives are of the d.c. series type, specially designed to work satisfactorily on the pulsating output from the singlephase rectifiers. Biphase or 'full-wave' rectification is used, the output from which can be conside:ed as a smooth d.c. voltage having superimposed on it an alternating e.m.f. of comparable magnitude and a frequency of $100 \mathrm{c} / \mathrm{s}$. This introduces problems of commutation and heating in the motors; but by paying special attention to the design of the motors and including smootbing choles in the circuit the difficulty can be overcome satisfactorily. With the ordinary d.c. system the problem does not arise, since rectifiers having six or more phases are used and the a.c. component or 'ripple' is in consequence insignificant.
The cost of the rectifier locomotive, according to the French figures, is comparable with a d.c. machine of the same rating, both in first cost and maintenance. Allowing for the improved performance, the rectifier machine shows a considerable economy in operating a given service. The use of semiconductor rectifiers in the future should show an even greater saving. The above-mentioned British survey shows that sixty fewer locomotives will be needed for these services.

'The provision of sufficient clearances for a contactline voltage of 25,000 volts is not easy in Britain. In some tunnels the cost of providing clearances would be prohibitive, and therefore it is proposed to omploy a much lower voltage, namely, 6,600 volts, over certain sections, combined with the use of dual-voltage equipment.

The taking of large amounts of single-phase power from the public supply network suggests problems of unbalance on the three-phase system. Experience in France has shown that any disturbance has remained within acceptable limits, and no trouble is anticipated in Britain with its more heavily-loaded grid. The proposed scheme has the full concurrence of the Central Electricity Authority.

In addition to its major advantages, the use of a.c. supply simplifies very considerably the supply of power to locomotive auxiliaries, train lighting and heating, ete., a single transformer sufficing to provide supplies at any voltage required.

It is evident that the British Transport Commission's choice of the $50 \mathrm{c} / \mathrm{s}$. alternating current system is based on a balanced judgment of the many factors involved. The Commission's readiness to profit by the latest technical developments is to be highly commended.

I would like to thank the Chief Electrical Engineer of the British Transport Commission for placing information relating to the proposed developments at my dispossal.

\title{
A NOTABLE BIOCHEMICAL JUBILEE
}

N 1906 Arthur Harden and William John Young, of the Lister Institute of Preventive Medicine, made two communications to the Royal Society of London on the alcoholic ferment of yeast juice; the first described the effect of phosphate on the rate of fermentation of glucose, and the second the separation from the juice by ultrafiltration of an inactive residue which could be re-activated by a soluble, heat-stable coenzyme in the filtrate.

Harden's experiments arose out of an attempt made with Allen Macfadyen to produce an antienzyme by the injection of yeast juice into animals, in the course of which it was found that normal serum increased the fermentation of glucose by yeast juice. In further experiments, Hardon and Young fortunately adopted a volumetric instead of a gravimetrie method, which enabled them to follow the rate of production of carbon dioxide continuously; they found that the filtrate from boiled yeast juice also increased the fermentation, with an initial rapid evolution of carbon dioxide, proportional in amount to the volume of juice added, and a prolongation of fermentation at a slightly higher basal rate. The effect was traced to the phosphates present in the juice, the extra carbon dioxide corresponding to one molecule for every atom of phosphorus added ais orthophosphate; after the fermentation the phosphate was present in a form not precipitated by ammoniacal magnesium eitrate, and presumed to be as an ester. The ester was afterwards identified by Young as fructose diphosphate; later, Harden and Robison found that a hexose monophosphoric ester was also formed which was shown by Robison to be an equilibrium mixture of glucose, fructose and mannose esters.

Harden and Young also dialysed the fresh juice, to find out the effect of the complete removal from the juice of the dialysable substances passing into the filtrate of boiled juice. They used for this purpose the rapid method of ultrafiltration under pressure through a filter of gelatin supported in tho pores of a Chamberland filter candle, which had been devised by C. J. Martin, then director of the Lister Institute. In this way, the juice was separated into a residue and a filtrate, each of which was itsolf incapable of fermenting glucose, but which together fermented it as actively as the original juice. Since soluble phosphates did not activate the residue, it was concluded 
that the filtrates contained a distinct factor, to which the name 'coenzyme' and later 'cozymase' was given.

Their work was simple but precise, and its very precision was perhaps a bar to their further elucidation of the phenomenon of phosphorylation. Harden perceived that inorganic phosphate was necessary for the rapid rate of fermentation, that is, the process of esterification was necessary; but it seemed that the ester formed (hexose diphosphate) could not be an intermediate, since it was only fermented very slowly by the juice. Harden and Young considered that a coupled reaction occurred :

$2 \mathrm{C}_{6} \mathrm{H}_{12} \mathrm{O}_{6}+2 \mathrm{HR}_{2} \mathrm{PO}_{4} \rightarrow$

$$
2 \mathrm{CO}_{2}+2 \mathrm{C}_{2} \mathrm{H}_{6} \mathrm{O}+2 \mathrm{H}_{2} \mathrm{O}+\mathrm{C}_{6} \mathrm{H}_{10} \mathrm{O}_{4}\left(\mathrm{PO}_{4} R_{2}\right)_{2}
$$

in which by the phosphorylation of one molecule of sugar the breakdown of a second molecule was induced; when all the inorganic phosphate was esterified, the rate of fermentation fell to the bassl rate, dependent for a supply of phosphate on the slow hydrolysis of the phosphoric esters.

It was not until 1945 that Meyerhof showed that the two phases were due to a destruction of the adenylpyrophosphatase of yeast during the proparation of the juice, so that the coupled reaction:
3-Glyceraldehydephosphate + phosphate + cozymase $\rightleftarrows$ 1-3 diphosphoglyceric acid +

dihydrocozymase

I-3 Diphosphoglyceric acid + adenosine diphosphate $\rightleftarrows 3$ phosphoglyceric acid + adenosine triphosphate came to a halt for lack of the phosphate-supplying mechanism of the apyrase :

Adenosine triphosphato $\rightarrow$

adenosine diphosphate + phosphate

Harden's facts, however, were incontrovertible and induced an autocatalytic fermentation in the science of biochemistry the course of which need not be recapitulated here. Though he realized the fundamental nature of his work, he was habitually restrained and would have thought it regrettable hyperbole 1.0 say to his colleague in 1906: "This day we have lighted such a candle in England as I trust shall never be put out". But it is no exaggeration to say now that their work is the source, reflected and amplified by many later workers, of our understanding of intermediary carbohydrate metabolism and many other phosphorylation mechanisms in animals, plants and micro-organisms.

\section{IMMUNOLOGICAL TOLERANCE}

\begin{abstract}
A MEETING was hold on March 8 at tho Royal A Society on the subject of "Immunological Tolerance", under the leadership of Sir Macfarlane Burnet. Following the definition of Billingham, Brent and Medawar, immunological tolerance is a specific weakening or suppression of reactivity caused by exposure of animals to antigenic stimuli before the maturation of the faculty of immunological response. In his opening paper, Prof. P. B. Medawar (University College, London) referred to the experimental demonstration of tolerance against such varied antigens as the erythrocyte agglutinogens, the tissue antigens responsible for transplantation immunity, bacterial antigens and purified proteins. Marked differences are found between the first two of these antigens: the erythrocyte antigens are stable, cytoplasmic, and elicit a transient gammaglobulin response, whereas the unstable, nuclear, tissue antigens elicit a permanent state of heightened graft resistance mediated by leucocytes rather than serum.
\end{abstract}

In contrast to the suppression of reactivity brought about by agents such as cortisone or radiation, tolerance is specific : the response to one antigen is suppressed without altering the response to others. Another essential property is that the suppression is central, acting on the tissue producing the antibody. Tolerance differs in this respect from immunological paralysis, or the enhancing of tumour growth by antiserum or tissue extracts. A comparable specific and central suppression of the immunological response has been demonstrated by Chase in the inhibition of sensitization to simple organic compounds by prior oral feeding. Medawar thon returned to the subject of the biological implications of immunological tolerance ${ }^{1}$.

In a paper on "Erythrocyte Antigens and Tolerance Phenomena", R. D. Owen (California Institute of Technology) drew two conclusions from his earlier work on stable erythrocyte mixtures in twin cattle. From the observation that the antigenic types derived from each twin occur in equal proportions in the blood of each twin, it follows that no selective pressure is exerted in favour of hæmatopoietic tissue of native origin, and that tolerance is therefore complete. From the observation that no more than two types of cell are found in twins which differ by several antigens (with the exception of $J$ ), it follows that sub-cellular transformations do not occur, and that hrmatopoietic cells are in this sense fully autonomous. Attempts to mimic the chimerism of twin cattle in rats by means of parabiosis have beon unsuccessful; but Ripley has produced a similar condition by injection of embryonic rats with embryonic liver and spleen cells through the chorionic blood vessels. Chimeras have also been produced in rats after injection of hæmatopoietic tissue into irradiated recipients, by Lindsley, Odell and Tausche. Owen then described his own work on acquired tolerance in man, where past exposure to $R h$ antigen in utero weakens the adult antibody response. $R h$-negativo women who complete three or more $R h$-positive pregnancies without developing antibodies tend to have $R h$-positive mothers. This tolerance is, however, not associated with a reduced incidence of erythroblastosis. Owen finally described an effect of injection of human erythrocytes into new-born chickens. The antibody response of the recipionts as adults is delayed, woakened and tends to the production of incomplete antibody.

B. Cinader and J. M. Dubert (Lister Institute and Institut Pasteur) gave an account of their joint work on "Specific Inhibition of Response to Purified Protein Antigens". New-born rabbits were injected with highly purified human albumen, and litter mates left as controls. When challenged with the same antigen as adults, the controls produced antibody detectable by a gel-diffusion technique, and also by agglutination of tanned erythrocytes coated with antigen. The animals injected at birth failed to produce antibody, constituting an example of actively acquired tolerance. Tolerance of the injected animals 